\title{
El desarrollo de las actividades productivas en la provincia de Chimborazo a través del microcrédito
}

\section{Chimborazo's productive activities development through microcredit}

Adriana Margarita Morales Noriega. ${ }^{1}$, Letty Karina Elizalde Marín. ${ }^{2}$ \& Gladys Verónica Morales Noriega. ${ }^{3}$

\begin{abstract}
.
DOI: $\quad$ https://doi.org/10.33262/cienciadigital.v3i3.3.814

The microcredit service purpose is to contribute activities carried out by families so that they can forge their own sources of employment and also for third parties, on the other hand, microcredit aims to generate sustained income as a measure of economic growth and thus ensure that families can escape poverty. The development levels and economic growth in Chimborazo's province are still low, since this economy has not been able to route the productive activities that it has in an adequate way. Today, the employment alternatives that the local population has found are carried out through the microcredit financing. In Chimborazo the number of Cooperative entities has proliferated, which direct their work in microcredits placement; However, there is an entity that has consolidated in the province and seeks the forging of the social and solidarity economy, Cooperativa de Ahorro y Crédito Riobamba Ltda. This research analyzes the entity microcredit participation, with the objective to measure if people who are benefiting from this service have been able to promote their productive activities and thus contribute to the development of the province. To provide an objective investigation, a sample of the Institution's partners will be determined, a survey will be applied in order to know their microcredit experience. The results derived from the study show the contribution that this institution's partners receive from microcredit service in the strengthening of their productive activities and at the same time the contribution to Chimborazo's province economy.
\end{abstract}

\footnotetext{
${ }^{1}$ Escuela Superior Politécnica de Chimborazo, Facultad de Administración de Empresas. Riobamba, Ecuador. adriana.morales@espoch.edu.ec

${ }^{2}$ Escuela Superior Politécnica de Chimborazo, Facultad de Administración de Empresas. Riobamba, Ecuador. letty.elizalde@espoch.fin.ec

${ }^{3}$ Cooperativa de Ahorro y Crédito Riobamba Ltda., Área de Planificación. Riobamba, Ecuador. planificacion@cooprio.fin.ec
} 
Keywords: Productive activities, Cooperative, social and solidarity economy, microcredit, partners.

\section{Resumen.}

El servicio del microcrédito tiene como finalidad aportar a las actividades que realizan las familias para que puedan forjar fuentes de empleo propias y también para terceros, por otro lado; el microcrédito pretende la generación de ingresos sostenidos como medida de crecimiento económico y así lograr que las familias puedan salir de la pobreza. Los niveles de desarrollo y crecimiento económico en la provincia de Chimborazo aún son bajos, ya que esta economía no ha podido encaminar las actividades productivas que posee de una manera adecuada. Hoy en día, las alternativas de empleo que ha encontrado la población de la localidad se las realiza a través del financiamiento de los microcréditos. En Chimborazo han proliferado el número de entidades Cooperativas, las cuales direccionan su trabajo en la colocación de microcréditos; sin embargo, existe una entidad que se ha consolidado en la provincia y busca el forjamiento de la economía social y solidaria, la Cooperativa de Ahorro y Crédito Riobamba Ltda. La presente investigación analiza la participación de la entidad en el ámbito microcrediticio, con el objetivo de valorar si las personas beneficiadas de este servicio han podido fomentar sus actividades productivas y así aportar al desarrollo de la provincia. Para aportar con objetividad la investigación, se determinará una muestra de los socios de la Institución, a los cuales se les aplicará una encuesta con la finalidad de conocer sus experiencias con el microcrédito. Los resultados derivados del estudio evidencian la contribución que reciben los socios de la institución por el servicio del microcrédito en el fortalecimiento de sus actividades productivas y a la vez el aporte al desarrollo de la economía de la provincia de Chimborazo.

Palabras claves: Actividades productivas, Cooperativa, economía social y solidaria, microcrédito, socios

\section{Introducción.}

Durante varios años, el Ecuador direccionó su economía bajo un modelo de desarrollo neoliberal, el mismo que limitó el desarrollo de la economía ecuatoriana, ya que el país dependía de otras economías a nivel mundial, por otro lado, no se reconocía al trabajo como articulador de la sociedad, pues se valoraba más al capital que el desarrollo de la población. El país se encontraba en un ambiente de total desintegración, pues no se reconocía la diversidad cultural, económica y social que existía en el Ecuador; la economía también presenció diversas crisis económicas, las cuales fueron el resultado del inadecuado accionar del capitalismo, en su momento el boom petrolero ocasionó que haya un excesivo endeudamiento por parte del Estado y finalmente existió la devaluación del sucre; estas etapas de la economía ecuatoriana provocaron una inestabilidad económica y política profunda.

El sistema financiero en el país, empezó a sentir las consecuencias del accionar económico inapropiado, específicamente en 1999, con la finalidad de evitar una hiperinflación, se 
restringió el desarrollo de operaciones financieras y se produjo el feriado bancario. Ante esta situación los clientes de las financieras empezaron a perder la confianza en el sistema bancario, posterior a ello, varias entidades bancarias cerraron sus puertas y otras perdieron un sinnúmero de clientes. Sin embargo, la economía ecuatoriana necesitaba contar con un sistema financiero confiable. Este escenario, significó una oportunidad para el sector de las Cooperativas de Ahorro y Crédito, pues con su silencioso accionar lograron ganarse la confianza de varios participantes del sistema financiero y así fortalecieron a los distintos sectores de la economía, en especial el de los sectores populares tradicionalmente excluidos.

El Sistema Cooperativo en el Ecuador tuvo sus inicios 1919, año en el cual se crea en Guayaquil la Cooperativa de Bienestar Social Protectora del Obrero, organización que se constituyó con la finalidad de servir a la población para satisfacer sus necesidades; con el pasar de los años este sistema ha podido consolidarse y hoy en día es el representante de la economía social y solidaria del país. Las instituciones de economía social y solidaria surgen en respuesta a la crisis del modelo de desarrollo, basadas en la democracia y en la solidaridad, además que su accionar se centra en la cooperación económica organizada; estas instituciones se respaldan en un pensamiento social en el cual el aspecto humano y ecológico también es considerado al momento de realizar las distintas actividades. Por otro lado, este sistema de economía social y solidaria vela por los intereses de la colectividad mediante un reparto equitativo de los ingresos generados de los procesos de producción, sobre todo en este espacio se pretende fomentar los sueños de la comunidad, a través de una verdadera justicia social para los diferentes sectores.

En la actualidad el Cooperativismo en el Ecuador busca la conciliación de productos y servicios financieros y no financieros, para satisfacer las necesidades, anhelos y proyecciones de los socios. El Sistema Cooperativo en el país rige su accionar bajo los siguientes principios y valores: solidaridad, ayuda mutua, participación democrática de sus asociados, propiedad social, capacitación, autogestión y compromiso con la sociedad. Las Cooperativas realizan actividades de inclusión financiera, ya que busca incluir a todos los sectores de la sociedad; tomando en cuenta que aún un alto porcentaje de la población no tiene acceso ni siquiera a una cuenta de ahorro en una institución financiera formal y por esta razón ni siquiera tienen la oportunidad de acceder a un crédito; los segmentos de la población que no tienen acceso al sistema financiero, generalmente se encuentran en las áreas rurales del país.

Las principales características que las Cooperativas de Ahorro y Crédito poseen son:

- Los titulares son sus asociados.

- El objetivo es brindar servicios y/o productos a sus asociados sin discriminación alguna.

- El control y dirección está en función de los asociados (un hombre un voto).

- El poder de elección se basa en el principio de igualdad, todos los asociados poseen los mismos derechos a opinar y votar.

- El capital es variable, de acuerdo al ingreso e egreso de los asociados, si un asociado se retira se le reintegra el valor de las cuotas sociales integradas.

- La condición de ingreso es libre sujeta a aprobación del resto de los asociados. 
- Las ganancias o excedentes se capitalizan o se distribuye entre los asociados en proporción a las operaciones realizadas o servicios prestados por los asociados; se basa en el principio de equidad.

Las Cooperativas centran sus actividades financieras en las microfinanzas, entendidas como el conjunto de acciones encauzadas a la prestación de servicios financieros que acojan a todos los sectores de la economía local y así impulsar el desarrollo de las actividades productivas. De acuerdo con lo establecido en los Objetivos de Desarrollo Sostenible, las microfinanzas, se presentan como una alternativa de cooperación en la solución de problemas de subdesarrollo y pobreza, este accionar se desarrolla a través de los tres supuestos básicos:

1. La exclusión del sistema financiero es una de las causas por las que las familias sufren de pobreza, el acceso a este sistema es conveniente para que las familias puedan superar este problema.

2. El acceso al crédito ayuda para que varias empresas puedan crearse, el emprendimiento también es clave para que las familias puedan ir generando ingresos para que puedan impulsar su desarrollo económico.

3. El microemprendimiento, ayuda a las personas que carecen de recursos económicos para que puedan ir creciendo económicamente.

Las microfinanzas tienen como objetivo el de ser una alternativa de desarrollo económico que cubra los problemas de: falta de empleo, economía informal, barreras de acceso al sistema financiero; sobre todo es una alternativa para que las personas pueden emprender sus propios negocios.

Los microcréditos son los servicios financieros que más promocionan las entidades microfinancieras, pues entregan a sus socios montos pequeños de dinero con la finalidad de que las familias pues iniciar y desarrollar sus actividades productivas propias, los cuales se extienden siempre y cuando exista viabilidad en las actividades que se van a potenciar. Los microcréditos son más demandados por las instituciones microfinancieras ya que han ayudado a que sus clientes logren desarrollarse, pero también las instituciones han visto la necesidad de crear otros servicios, como por ejemplo los seguros de vida y de enfermedad, que son ahora un producto que todas las instituciones brindan a sus socios, los programas de vivienda también son comunes hoy en día, todos estos ayudan a que los microempresarios puedan ir creciendo en todos los ámbitos, no únicamente en el aspecto económico sino también tanto en su vida personal diaria.

La mayoría de los microcréditos han sido concedidos para que muchas microempresas se formen, y han ayudado a dinamizar de la economía, debido a que emplean a muchas personas que usualmente poseen ingresos medios y bajos, y ayuda a que varias personas no continúen en situación de desempleo. Además, el microcrédito asiste a que la gente pueda tener su propio empleo y que a largo plazo sus ingresos y niveles de consumo se incrementen. 
Los microcréditos poseen las siguientes características:

1) Los montos de otorgamiento son bajos.

2) Los beneficiarios son familias de escasos recursos, en su mayoría mujeres.

3) El objetivo de los microcréditos es reducir la pobreza a través de la generación de actividades de autoempleo o actividades de emprendimiento, también son otorgados para cuestiones de vivienda, no se otorgan para cubrir gastos de consumo.

4) La garantía máxima es la confianza, no se basan en una garantía física.

5) Para obtener microcréditos es óptimo que se integren grupos de personas, pues generan capital social.

6) La garantía es colectiva, con responsabilidad subsidiaria de todo el grupo.

7) Los microcréditos se otorgan bajo propia selección y tienen un sistema personalizado, en el cual las instituciones microfinancieras acuden al cliente, no el cliente a las instituciones.

8) El pago de interés y devolución del nominal es en base a pagos regulares y plazos frecuentes.

9) La cantidad ofrecida en cada nuevo crédito es creciente, y está condicionada por los pagos anteriores a todo el monto otorgado anteriormente.

10) Junto al otorgamiento de microcréditos, también se pide al cliente que tengan una cultura de ahorro en la institución.

11) Los tipos de interés que se fijan, es para mantener la sostenibilidad del servicio.

12) Las instituciones que brindan los microcréditos son generalmente instituciones sin fines de lucro (Cooperativas de Ahorro y Crédito).

Es importante mencionar que un país para alcanzar adecuados niveles de crecimiento económico es importante también que cuente con un amplio acceso a los servicios financieros, porque de esta manera se logrará una economía incluyente para todos y todas, en la cual la población posea condiciones de vida de calidad y óptimas.

En la provincia de Chimborazo, una de las instituciones encargadas de fortalecer la economía social y solidaria del país, es la Cooperativa de Ahorro y Crédito Riobamba Ltda., declarada en el 2018 por la Revista Gestión como la mejor entidad financiera entre las entidades medianas y grandes, lo cual se alcanzó por su adecuado desempeño en la prestación del servicio microcreditico y los adecuados niveles de rentabilidad que ha ido generando año tras año. Además, esta institución cuenta con niveles adecuados en la administración de riesgo, solvencia y liquidez; ante este escenario se considera que la Cooperativa Riobamba es una alternativa de desarrollo económico para la provincia de Chimborazo, ya que aporta a la generación de fuentes de trabajo y progreso de los distintos sectores de la economía.

\section{Metodología.}

La investigación realizada es de tipo descriptiva, ya que el análisis se realizará en base a hechos que han ocurrido durante los últimos años y en base a los mismos se dará una interpretación económica. El estudio se respaldará en la estadística como herramienta principal, mediante la cual se realizará un análisis de cada una de las variables que se estudien de manera separada, con la finalidad de determinar el impacto que tiene el microcrédito 
otorgado por la Cooperativa Riobamba en la economía de los socios. Para desarrollar la investigación, se aplicará una encuesta a una muestra del total de socios de la Cooperativa. Los datos obtenidos de las encuestas realizadas a los socios de la institución permitirán observar la tipología de los clientes, sectores a los que beneficia el microcrédito, el éxito en los negocios de los microempresarios y la satisfacción de los socios. Estos datos permitirán un realizar una adecuada interpretación y análisis del microcrédito en la provincia de Chimborazo.

El análisis de la encuesta se realizará a una muestra de los socios pertenecientes a la provincia de Chimborazo y se recogerá sus experiencias obtenidas con el beneficio del microcrédito. El número de socios a los cuales se aplicará la encuesta se determinará mediante la siguiente fórmula:

$$
n=\frac{Z^{2} \sigma^{2} N}{e^{2}(N-1)+Z^{2} \sigma^{2}}
$$

$\mathbf{n}=$ tamaño de la muestra

$\mathbf{N}=$ tamaño de la población, número total de socios en la provincia de Chimborazo (65.170)

$\boldsymbol{\sigma}=$ desviación estándar de la población $(0.5)$

$\mathbf{Z}=$ valor obtenido mediante los niveles de confianza de $95 \%$ que equivale a $(1,96)$

$\boldsymbol{e}=$ límite aceptable del error muestral (0.05)

La muestra asciende a un total de 381 socios.

\section{Resultados.}

La Cooperativa Riobamba se ha enfocado en desarrollar sus actividades microcrediticias de manera activa y permanente, con la finalidad que los socios de la institución logren la consolidación de sus negocios, emprendimientos y fortalecimiento de las actividades productivas que realiza; ya que a través de estos parámetros son generadores de fuentes de empleo y aportan al desarrollo de la localidad.

El microcrédito se ha convertido en una herramienta indispensable para iniciar y fortalecer las actividades económicas que realizan los socios, ya que, al no poseer el capital suficiente, la Cooperativa Riobamba otorga este servicio para apoyar los distintos proyectos y así cubrir las necesidades financieras de capital que posean los microempresarios y de esta manera se consolidar cada una de las actividades establecidas por los socios de esta entidad.

El servicio del microcrédito en la Cooperativa Riobamba hoy en día es uno de los servicios más representativos de la institución, ya que cada vez más familias demandan el mismo para forjar sus actividades productivas, entre las actividades productivas que los microcréditos de la institución apoyan están los siguientes: 
Tabla 1: Participación del mercado de captaciones de la provincia de Chimborazo

\begin{tabular}{lcc}
\hline \multicolumn{1}{c}{ ACTIVIDAD PRODUCTIVA } & PARTICIPACION & MOROSIDAD \\
\hline Transporte de pasajeros por vía terrestre & $13,81 \%$ & $1,55 \%$ \\
Comercio al por menos de alimentos (productos agrícolas e & $8,23 \%$ & $2,38 \%$ \\
industrializados) & & \\
Transporte de carga por vía terrestre & $5,37 \%$ & $0,64 \%$ \\
Comercio al por menos de otros productos & $5,03 \%$ & $1,89 \%$ \\
Construcción de edificios & $4,83 \%$ & $1,11 \%$ \\
Producción de leche cruda o fresca de cualquier tipo & $4,36 \%$ & $1,10 \%$ \\
Servicios de alimentos, bebidas y otros servicios de comidas & $4,09 \%$ & $2,92 \%$ \\
móviles & & \\
Comercio al por menos de prendas de vestir & $3,04 \%$ & $2,78 \%$ \\
Fabricación de prendar de vestir y tejidos de ganchillo & $2,57 \%$ & $2,51 \%$ \\
Cultivo de tomate & $2,42 \%$ & $0,82 \%$ \\
Servicios de reparación y mantenimiento de vehículos de & $1,87 \%$ & $1,40 \%$ \\
motor y motocicletas & & \\
Actividades inmobiliarias & $1,79 \%$ & $0,58 \%$ \\
Actividades de Cooperativas & $1,64 \%$ & $0,20 \%$ \\
Otras actividades de servicios & $1,61 \%$ & $1,52 \%$ \\
Elaboración de productos de la panadería y pastelería & $1,27 \%$ & $3,75 \%$ \\
Cultivo de papa & $1,27 \%$ & $0,37 \%$ \\
Comercio al por menor de ferretería & $1,21 \%$ & $1,49 \%$ \\
Fabricación de productos metálicos para uso estructural & $1,17 \%$ & $1,98 \%$ \\
Cría de cerdos & $1,13 \%$ & $2,59 \%$ \\
Comercio al por mayor de otros productos agrícolas & $1,11 \%$ & $2,00 \%$ \\
Otras actividades & $32,17 \%$ & $1,86 \%$ \\
TOTAL & $100,00 \%$ & \\
\hline
\end{tabular}

Fuente: Cooperativa de Ahorro y Crédito Riobamba Ltda.

Los resultados derivados de la encuesta realizada a los 381 socios son los siguientes:

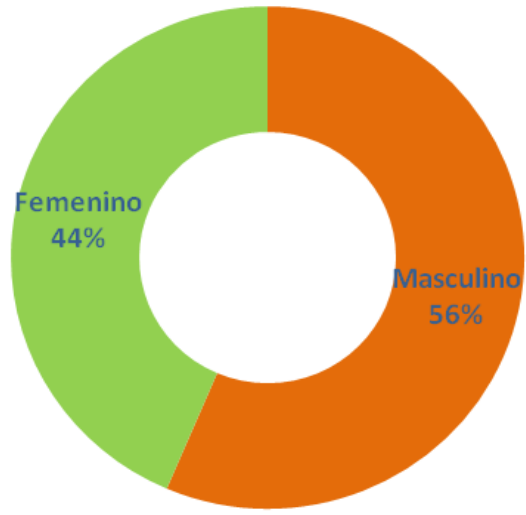

Figura 1: Género

Fuente: Encuesta socios

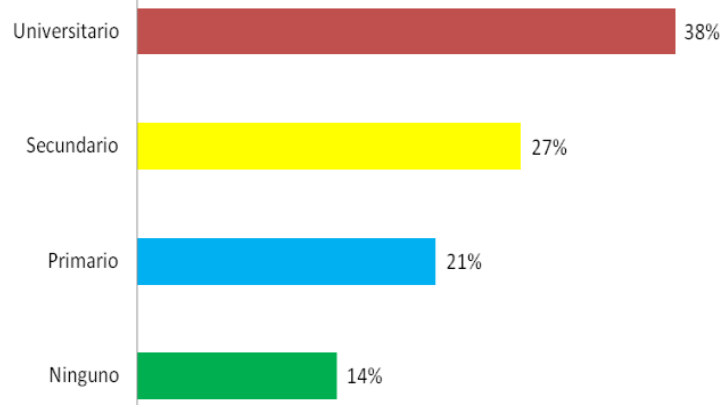

Figura 2: Nivel de estudios

Fuente: Encuesta socios 


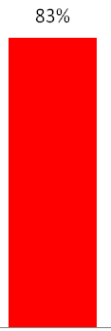

Créditos

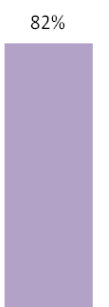

Ahorros
Pagos y Transferencias

Figura 3: Servicios financieros demandados

Fuente: Encuesta socios

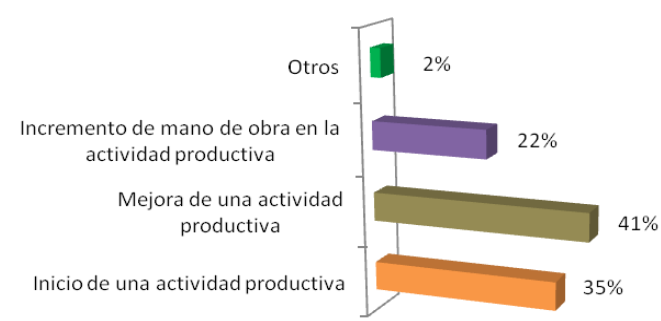

Figura 5: Destino microcréditos obtenidos Fuente: Encuesta socios

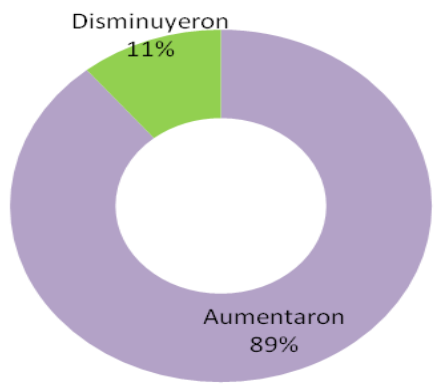

Figura 7: Nivel de ingresos después de la obtención de los microcréditos

Fuente: Encuesta socios

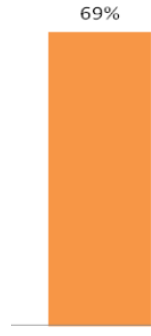

Aumentó

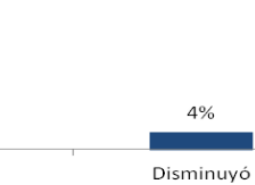

Disminuyó

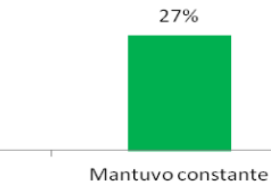

Figura 9: Número de empleados en los establecimientos de los socios

Fuente: Encuesta socios

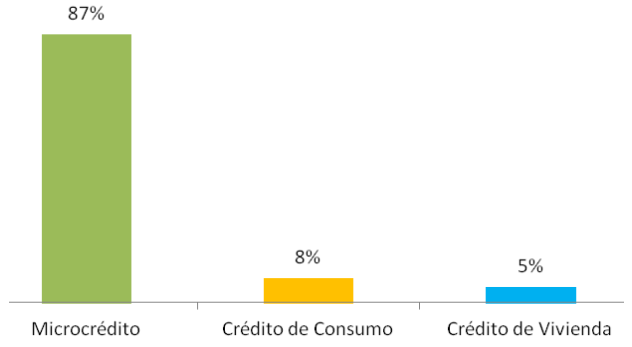

Figura 4: Tipos de crédito demandados Fuente: Encuesta socios

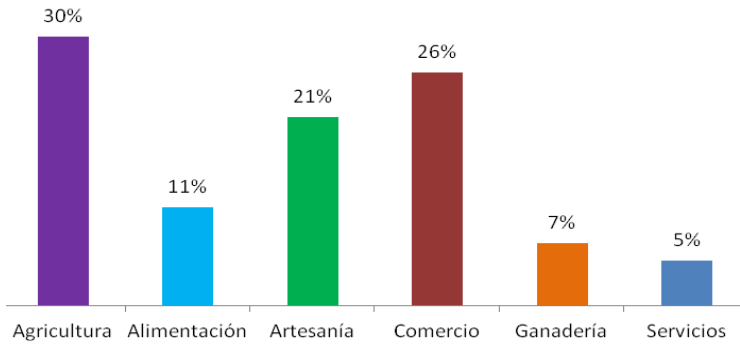

Figura 6: Dedicación a las actividades productivas Fuente: Encuesta socios

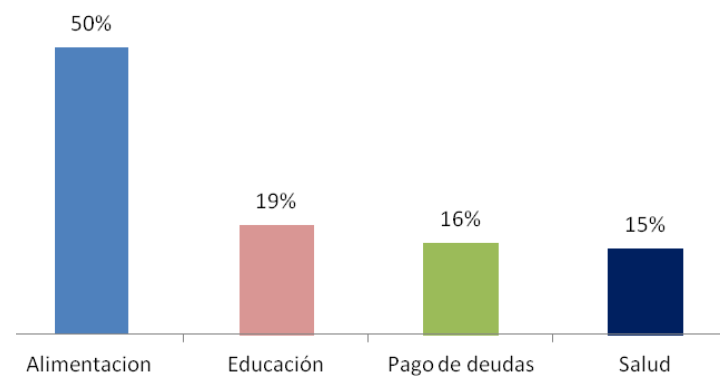

Figura 8: Destino de los ingresos mensuales recibidos Fuente: Encuesta socios

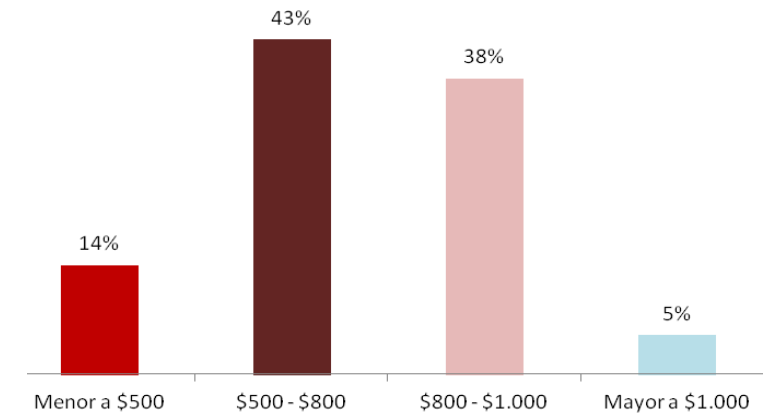

Figura 10: Valor de la producción mensual de los socios Fuente: Encuesta socios 


\section{Discusión.}

El mayor número de socios pertenecientes a la Cooperativa Riobamba, demandan el servicio del microcrédito, ya que a través de este cada vez más familias pueden impulsar y desarrollar las actividades productivas que realizan; y así ser generadores de sus propios negocios y así tener un empleo estable que permita la satisfacción de las necesidades que las familias poseen.

De acuerdo con los resultados derivados de la encuesta realizada a los socios, se evidencia que el 56\% de ellos son hombres, Ver Figura 1, la razón por la cual este porcentaje es menor al que las mujeres, es debido a que casi en su totalidad los encuestados son jefes de hogar y son quienes poseen un empleo más estable; únicamente el $44 \%$ de las personas encuestadas fueron mujeres. Tanto hombres como mujeres acuden a demandar los microcréditos para fortalecer y generar sus actividades productivas. Por otro lado, los negocios establecidos por los hombres en un $86 \%$ se encuentran aún en funcionamiento y en el caso de las mujeres, el $81 \%$ de los negocios establecidos siguen brindando sus servicios. Estos datos evidencian que los establecimientos puestos en funcionamiento por los socios de esta entidad, tiene un nivel de éxito apropiado.

En un gran porcentaje, la población de la provincia de Chimborazo proviene de las zonas rurales, razón por la cual el nivel de estudios que poseen es escaso, solo el $38 \%$ de los socios de la Cooperativa tienen instrucción académica universitaria, Véase Figura 2, el 14\% de ellos no tiene ningún tipo de instrucción académica ya que varias familias desde una edad muy temprana deben dejar los estudios para salir a trabajar para contribuir en la economía del hogar. La mayor cantidad de actividades productivas que realizan los socios de la institución, Véase Tabla 1, no requieren de una instrucción académica específica, razón por la cual la escasa formación académica no ha influido en la ejecución de las distintas actividades, pues en su mayoría los negocios han logrado consolidación en el mercado.

Los socios encuestados han manifestado que acuden a la entidad por el adecuado servicio que brindan y también por la confianza que se ha generado. Entre los servicios demandados por los socios se encuentran los ahorros, pagos-transferencias y créditos, Véase Figura 3, específicamente el $83 \%$ de los socios acuden a la entidad para demandar créditos, ya que los mismos les permite tener el capital necesario para emprender las distintas actividades que buscan desarrollar. De los créditos ofertados por la Cooperativa, el $87 \%$ de ellos son microcréditos, Véase Figura 4, los cuales, de acuerdo con los socios, les ha permitido mejorar la economía de sus familias.

Considerando las caracteristicas del sector chimboracense en el ámbito económico-social y con la finalidad de aportar el el desarrollo de la economía de la provincia y también, para fortalecer los negocios, el $41 \%$ de los socios la población realiza actividades productivas, Véase Figura 5, ya que el desarrollo de las mismas permite que los socios puedan empezar su propia microempresa, la misma que les servirá para mejorar su propia economía propia y de la provincia. 
El 35\% de los socios demandan el servicio para inciar una microempresa con sus actividades productivas que realizan. Por otro lado, un total de 133 encuestados han aperturado su negocio propio con la ayuda del microcredito, de ellos el $88 \%$ continuan con el negocio debido al exito que ha tenido, la misma que ha sido posible por el direccionamiento obtenido por parte de la entidad. Al haber prosperidad en las microempresas emprendidas por los socios, estos se ven con la necesidad de ampliar sus negocios por lo que necesitan mayor número de personas que trabajaen en el negocio. Los socios beneficiados de microcreditos coinciden que sus actividades productivas han podido desarrollarse debido al apoyo constante que han encontrado en la Cooperativa Riobamba, además han podido salir adelante, sus ingresos económicos han mejorado y también han podido ser fuente de empleo para más personas lo que ha permitido que tanto sus familias como las de sus empleados gocen de condiciones de vida mejores.

Las necesidades de la población, debido a los microcréditos ha podido ser cubiertas de alguna manera, ya que el $84 \%$ de los encuestados, una vez que perciben sus ingresos, destinan los mismos para alimentacion, salud y educación, Véase Figura, lo cual evidencia el aporte de los microcréditos para el impulso de la economía local. La necesidad de contar en la provincia con mayores fuentes de empleo es evidente, sin embargo, los socios encuestados han manifestado que el microcrédito ha aportado al desarrollo de las actividades productivas de manera adecuada, en las cuales los ingresos se incrementan, actualmente los socios perciben entre $\$ 500$ - \$1.000. El 69\% de los socios analizados han podido aumentar el número de empleados, Véase Figura 10, y el $27 \%$ ha podido mantener a todos sus empleados con un trabajo establece; estos datos demuestran que las actividades derivadas o fortalecidas con los microcréditos son generadoras de fuentes de empleo.

\section{Conclusiones.}

- La provincia de Chimborazo al ser una localidad en la cual el mayor número de habitantes provienen de zonas rurales, sus fuentes de empleo se enfocan en el fortalecimiento de las actividades productivas, las cuales cada vez se consolidan en el mercado chimboracense gracias al financiamiento recibido por la Cooperativa Riobamba, a través de los microcréditos.

- Los microcréditos en el accionar de la economía de la localidad, resultan ser indispensables, ya que los mismos permiten que los socios de la Cooperativa posean los recursos necesarios para iniciar las actividades económicas que pretenden desarrollarse para impulsar el desarrollo de la economía de sus familias.

- La utilización del microcrédito ha permitido que varias familias mejoren su bienestar económico y social. Los socios beneficiarios de los microcréditos han desarrollado sus propias microempresas las cuales a la vez han sido generadoras de empleo, esto demuestra que la creación de estos negocios no únicamente mejora el bienestar del socio, sino que también aporta al desarrollo económico y social de la provincia de Chimborazo.

- Los microcréditos entregados por la Cooperativa Riobamba, en gran porcentaje han permitido una mayor generación de ingresos en la familias socias y así cada vez las necesidades de la población han podido ser cubiertas. 


\section{Referencias Bibliográficas.}

Acosta, A. (2014). Buen Vivir - Sumak Kawsay. Una oportunidad para imaginar, Icaria, Barcelona.

Bicciato, F. (2002) Microfinanzas en países pequeños de América Latina: Bolivia, Ecuador y El Salvador. Santiago de Chile: CEPAL

Cabezas, G. (2008). Las cooperativas de ahorro y crédito reguladas y su aporte en el desarrollo del microcrédito en el Ecuador. (Disertación de grado a la obtención del título de Economista), Pontificia Universidad Católica del Ecuador, Quito-Ecuador.

Cordovez, J. \& Estrella, H. (2004). Las Microfinanzas en la Economía Ecuatoriana: un aporte al desarrollo económico. Facultad Latinoamericana de Ciencias Sociales. Quito. Recuperado desde: http://www.flacso.org.ec/docs/microec.pdf

Ministerio de Economía y Finanzas. (2018): “Plan de Prosperidad 2018 - 2021”, Quito.

Muller, Steffen (2010). Estudio sobre los mercados microcrediticios en países selectos de Latinoamérica. DGRV: Confederación Alemana de Cooperativas. Asunción. Recuperado desde:

http://www.cemla.org/old/actividades/2010/2010-05EducacionFinanciera/MicrofinanzasCEMLA-DGRV.pdf.

Pedroza, P. (2012), El Sector microfinanciero Cooperativo en América Latina y el Caribe. Fondo Multilateral de Inversiones. http://www.microfinanzas.org.uy/archivos/pdf_hch_27_12.pdf.

Saldaña, J. V. (2015). La Constitución Económica del Ecuador . Iuris Dictio. Revista de Derecho, 121-148.

Secretaria Nacional de Planificación y Desarrollo. (2017). Plan Nacional de Desarrollo 2017 -2021, Quito.

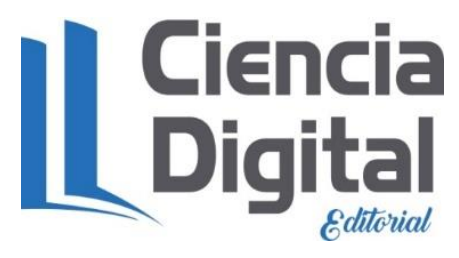


PARA CITAR EL ARTÍCULO INDEXADO.

Morales Noriega, A., Elizalde Marín, L., \& Morales Noriega, G. (2019). El desarrollo de las actividades productivas en la provincia de Chimborazo a través del microcrédito. Ciencia Digital, 3(3.3), 274285. https://doi.org/10.33262/cienciadigital.v3i3.3.814

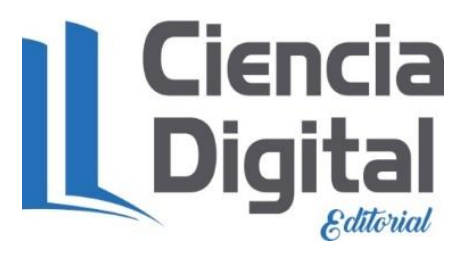

El artículo que se publica es de exclusiva responsabilidad de los autores y no necesariamente reflejan el pensamiento de la Revista Ciencia Digital.

El artículo queda en propiedad de la revista y, por tanto, su publicación parcial y/o total en otro medio tiene que ser autorizado por el director de la Revista Ciencia Digital.
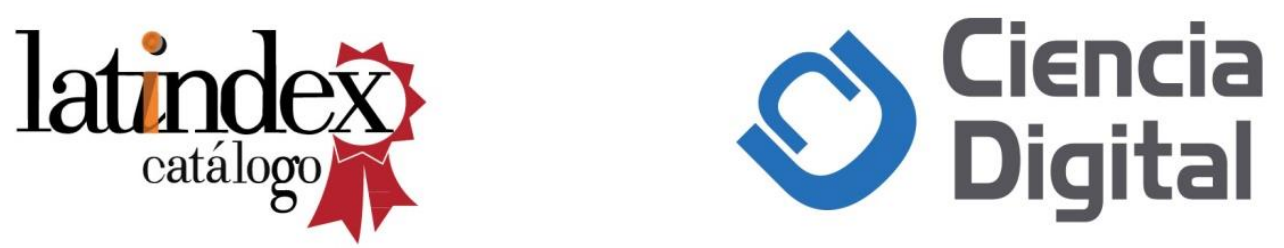